\title{
Anas Huneety
}

Hashemite University, Jordan

Omer AlHajEid

UNRWA Education Institute, Jordan

\section{Attitudes toward Jordanian Arabic-Accented English among Native and Non-native Speakers}

\begin{abstract}
This paper explores attitudes toward Jordanian Arabic-accented English among native and non-native speakers of English. Three groups of listeners (native English speakers, Jordanian Arab specialists and non-specialists in English) were asked to rate three groups of speakers (a group of native English speakers and two groups of Jordanian Arabic bilinguals) reading a short story in English on the degree of foreign accentedness, friendliness, pleasantness and clarity. The results showed that the Jordanian Arabic speakers, especially those with a lower level of English, were perceived less favourably than the native speakers. Furthermore, the English native listeners generally had more favourable perceptions than the non-native listeners with regard to the non-native speakers. The degree of foreign-accentedness was highly correlated with attitudes toward non-native speakers, especially among the non-native speakers themselves. The results confirm that a native English accent is preferred over nonnative accents.
\end{abstract}

Keywords: foreign accent, Jordanian Arabic, attitudes, friendliness, pleasantness, clarity

\section{Odnos do angleščine z jordansko-arabskim naglasom pri maternih in tujih govorcih angleščine}

\author{
IZVLEČEK
}

Namen prispevka je raziskati odnos do angleščine z jordansko-arabskim naglasom pri maternih in tujih govorcih angleščine. Tri skupine poslušalcev (materni govorci angleščine, strokovnjaki za jordansko-arabski jezik in nestrokovnjaki za angleščino) so morale oceniti tri skupine govorcev (skupino maternih govorcev angleščine in dve skupini dvojezičnih govorcev jordanske arabščine), ki so morali prebrati kratko zgodbo v angleščini. Poslušalci so ocenjevali stopnjo tujega naglasa, prijaznost, prijetnost in jasnost. Rezultati so pokazali, da so bili govorci jordanske arabščine, zlasti tisti z nižjo stopnjo znanja angleščine, zaznani manj ugodno kot materni govorci angleščine. Poleg tega so bili angleški materni poslušalci na splošno bolj naklonjeni tujim govorcem kot tuji poslušalci. Stopnja tujega naglasa je bila močno povezana z odnosom do tujih govorcev, še posebej med samimi tujimi govorci. Rezultati potrjujejo, da je materni angleški naglas bolj zaželen kot tuj naglas.

Ključne besede: tuj naglas, jordanska arabščina, odnosi, prijaznost, prijetnost, jasnost 


\section{Introduction}

Although some linguists argue that a foreign accent (FA) is natural and unavoidable, and does not cause problems as long as it does not compromise intelligibility (e.g., Seidlhofer 2001; Jenkins 2007), many others report that not only does an FA interfere with intelligibility and comprehensibility (e.g., Ryan 1983; Giles et al. 1987; AndersonHsieh and Koehler 1988; Munro and Derwing 1995; Cargile and Giles 1998; Nguyen and Ingram 2016), but also with perceptions of speakers in terms of social status and competence (e.g., Bresnahan et al. 2002; Deterding and Kirkpatrick 2006). Munro and Derwing (1995), for example, found that foreign-accented speech affected intelligibility and comprehensibility as it required more time and effort to process. Additionally, many studies have demonstrated that foreign-accented speech was perceived less favourably than standardized accents, leading to the formation of stereotypes among listeners with a considerable effect on a speaker's status, competence and even work opportunities (e.g., Carlson and McHenry 2006; Deprez-Sims and Morris 2010).

Investigating reactions to FAs sheds light on the stereotypes people tend to attribute to speakers with them. Such evaluations represent people's attitudes, which have a great impact on how they deal with and see others with respect to status and competence (McKenzie 2008, see Section 2 below). Studying such reactions to foreign-accented speech is of crucial importance to both native speakers (NSs) and non-native speakers (NNSs). These reactions would benefit L2 learners by making them aware of the stereotypes associated with the presence of FAs. Moreover, studying the attitudes of NNSs toward their accents is very important inasmuch as it raises learners' awareness of their own stereotypes, prejudices, as well as expectations (Friedrich 2000).

Similarly, NSs would become better aware of the prejudices and misconceptions against foreign-accented speech. For example, teachers, administrators and all stakeholders would be aware that FAs should not interfere with their perceptions of other traits. People tend to judge L2 speakers negatively on traits that are independent of accentedness, such as friendliness and intelligence, only because they speak with a strong FA (Carlson and McHenry 2006; DeprezSims and Morris 2010).

Studies dealing with attitudes toward Arabic-accented English are rare. No previous study, as far as we know, has dealt with reactions to Jordanian Arabic (JA)-accented English. This study attempts to fill the gap in the literature by exploring the reactions of English NSs and JA specialist and non-specialist bilinguals (see Section 3) toward JA-accented English. More specifically, the present study will address the following research questions:

RQ1. How do English NSs, specialist and non-specialist JA bilinguals perceive JAaccented English in terms of the degree of accentedness, friendliness, pleasantness and clarity?

This will be measured on a scale from 1 to 9 , with 1 being the best and 9 the worst (see Appendix). Using a nine-point scale follows the most common approach in accentedness research (e.g., Riney, Takada, and Ota 2000; Yeni-Komshian, Flege, and Liu 2000; Munro and Derwing 2001). 
RQ2. Do English NSs, specialist and non-specialist JA bilinguals perceive JA bilinguals similarly?

RQ3. To what extent does the degree of accentedness influence the perception of the other attributes?

RQ4. To what extent are the other attributes correlated?

To answer research questions 3 and 4, we will use Pearson correlation tests to find out how much they are correlated.

Drawing on earlier studies (cf. Section 2), we adopt the following definitions of terms in this paper. Accentedness refers to how strong a speaker's FA is perceived to be. Friendliness refers to how the accent is felt to be in terms of kindness and agreeableness, as opposed to hostility or aggressiveness. Pleasantness relates to how charming, musical/melodious the accent is felt. Clarity refers to how clear and easy to understand an accent is felt to be.

The rest of this paper is organized as follows. In Section 2, we review earlier research on FAs and their role in the perception of speakers in terms of other traits. In Section 3, we lay out the methods used to collect the data and in Section 4 we present the results. Section 5 discusses the results and concludes with some implications to foreign language pronunciation.

\section{Previous Research}

In this section, we review studies that dealt with reactions to non-standardized accents (both regional and foreign) and show that there is a dearth of studies on attitudes toward Arabicaccented (especially JA) English.

Previous research has shown that a speaker's accent plays a major role in listeners' judgements; listeners usually prefer standardized accents to non-standardized ones, which are usually stigmatized and perceived to indicate lower status, lower intelligence, lower competence and lower loyalty (e.g., Lambert, Frankel, and Tucker 1966; Brennan and Brennan 1981; Fuertes, Potere, and Ramirez 2002; Gluszek and Dovidio 2010).

In particular, foreign language speakers were usually perceived less positively than NSs based on the accentedness of their speech, leading to the association of certain stereotypes with them (e.g., Bresnahan et al. 2002; Frumkin 2007). Moreover, the heavier their FAs, the more negatively their personalities were perceived (Lindemann 2005; McKenzie 2008; among others). Other studies found that people's accents also influenced their interpersonal evaluations and employment opportunities (e.g., Carlson and McHenry 2006; Frumkin 2007; Cargile et al. 2010). A standardized accent was found to be associated with higher social status and attractiveness, better employment opportunities, higher intelligence, and more trustworthiness (Coupland and Bishop 2007; Fuertes, Potere, and Ramirez 2002).

Likewise, accentedness was reported to affect perceptions of teachers (Giles et al. 1987; Rounds 1987; Rubin and Smith 1990; Gill 1994; Hendriks, van Meurs, and Reimer 2018). For example, Gill (1994) analysed American students' attitudes toward their teachers with native and non-native accents and found that teachers with standardized North American 
accents received more positive reactions than teachers with non-native accents, and accentedness intervened with comprehension whereby students found it more difficult to remember Malaysian or even British-accented teachers than North American-accented ones. Other researchers showed that these attitudes existed in other fields, such as health and law, whereby people with FAs were perceived as less competent, less educated and less trustworthy than people with native accents (Lippi Green 1997; Garrett 2010; Gluszek and Dovidio 2010; Lev-Ari and Keysar 2010).

In the rest of this section, we focus on studies dealing with (foreign) accented-English and divide them into three categories: 1. studies that addressed English NSs' reactions to FAs, 2. studies that dealt with NNSs' reactions, and 3. studies that dealt with both NSs' and NNSs' reactions.

Many studies have investigated English NSs' reactions to foreign-accented speech. Eisenhower (2002) analysed American NSs' attitudes toward ethnic and foreign accents. She found that her college American participants favoured standardized American English accents while they downgraded accented speech. Watanabe (2008) analysed New Zealanders' attitudes and found that a New Zealand accent was generally more preferable than FAs and even other English native accents in terms of solidarity, competence and status traits. However, some FAs (e.g., French-accented English) received favourable reactions that were comparable to native accents of English with respect to status traits, a finding that contradicts most other research on FAs.

Cargile et al. (2010) investigated how American NSs perceived 14 male NNSs with Spanish, German, Italian, Mandarin, Hindi, and Vietnamese backgrounds. They found that Americans generally perceived the Latin American and Asian speakers to be more foreign-accented than the Western European speakers, except for the Italian one. Moreover, the participants perceived the American NSs to have the highest status, followed by the German speakers, Hindi and Mandarin and Italian speakers, respectively, and the Vietnamese and Spanish speakers to have the lowest status. In terms of friendliness and kindness, all speakers were perceived similarly with no significant differences, which is in line with most research on non-native evaluations in the USA. In a very recent study, Dragojevic and Goatley-Soan (2020) examined American NSs' attitudes toward standardized American English and nine NNSs, including one Arabic speaker. They found that non-native accents were rated less positively than the American accent with respect to status and solidarity with some differences in the degrees of rating the non-native accents; the Western European-accented speech was judged to be more favourable than the Arabic-, Farsi-, and Vietnamese-accented speech. They attributed the differences in the ratings to the social power of English and Western European countries, and the degree of ease with regard to understanding a speaker's speech - the easier it was to understand the speakers, the more positively they were rated.

Studies investigating NNSs' reactions toward foreign-accented speech reached similar conclusions. Chiba, Matsuura and Yamamoto (1995) analysed Japanese students' judgments of the personalities of English NSs and Japanese learners of English. They found that the Japanese students perceived people with non-native accents to have lower social status, lower intelligence, and lower educational levels than people with native accents. Similarly, DaltonPuffer, Kaltenboeck, and Smit (1997), comparing students' attitudes to English native 
accents and Austrian-accented English, reported that non-native accents were accorded less status than native English accents, with the British RP accent receiving the highest status as a consequence of the students' familiarity with it.

McKenzie (2008) analysed reactions to Japanese-accented English and found a strong correlation between Japanese-accented English and perceived lower competence, such that the more Japanese-accented a speaker was, the lower competence they were judged to have. In contrast, Japanese-accented speakers were perceived more favourably than with speaking native accents in terms of solidarity traits, most probably as an in-group marker. Ahmed, Abdullah and Heng (2014) analysed Malaysian university students' attitudes toward six lecturers in Malaysian universities, two with American and British accents and four with non-native accents, namely, Arabic, Chinese, Malay, and Indian. Contrary to most previous research, they found a preference for non-native accents, a finding that was attributed to ingroup preferences. The non-native accents were perceived to be better with respect to eight traits such as clarity, solidarity, confidence, intelligence and familiarity. Their results were in line with Tajfel and Turner's (1986) Social Identity Theory, which argues that people tend to show preferences towards their social group members.

More recently, Hendriks, van Meurs and Reimer (2018) analysed how Dutch and German students perceived Dutch- and German-accented English of lecturers in universities. They concluded that the more accented the speech was, the less positive it was judged to be, such that lecturers with moderate Dutch and German accents were rated less favourably than slight non-native accented speakers who were perceived as being almost as competent, likeable and intelligible as native English lecturers. Lin, Choo, Kasuma and Ganapathy (2018) surveyed Malaysian BA students' attitudes toward their Malaysian-accented English. They reported that the Malaysian students perceived their accents positively, although they acknowledged that their Malaysian-accented English was a substandard accent that was not very suitable for international communications.

Fewer studies have compared both NSs' and NNSs' attitudes toward foreign-accented English, and hence more studies are needed to shed more light on these perceptions (Said 2006; Hendriks, van Meurs and Reimer 2018). A study by Brennan and Brennan (1981) compared Anglo-American and Mexican American evaluations of Mexican Americanaccented speech. Using a seven-point rating scale with bipolar adjectives (e.g., trustworthyuntrustworthy) placed on each side of the scale, Brennan and Brennan found that the more accented the speech was, the more negatively it was perceived by both groups with respect to status (education, wealth, success, and intelligence) but not with respect to solidarity (trustworthiness. friendliness, goodness, and kindness) where Mexican Americans perceived the Mexican-accented speech more positively.

Likewise, Said (2006) investigated native American and non-native East and South-East Asian speakers' attitudes toward eight speakers with foreign-accented English (including two Arabs). He found that lower degrees of accented speech were correlated with higher status, while higher degrees of accentedness correlated with lower status, particularly regarding the speakers' possible occupation. However, no correlation between accented speech and solidarity judgments was found for either group. He also reported that native 
and non-native evaluations differed significantly, and the raters' gender also played a role, though to a lesser degree, in the evaluations of accented speech, with females being more tolerant of accentedness than males. Moreover, he found that NNSs were more tolerant of accented speech, a tendency that reflects the speakers' awareness of the many challenges that NNSs face acquiring a native-like accent. Although the male Arab speaker received fewer positive evaluations than the other NNSs, no definite conclusions can be drawn from this observation as it is based on the evaluations of one speaker only, which could be an idiosyncratic one.

To summarize, earlier research pointed out that foreign-accented speech was usually perceived less positively with respect to status and competence but not with respect to solidarity traits. The results were accounted for in terms of in-group behavior and the Social Identity Theory, which postulates that people attribute certain stereotypes to certain social groups (Brennan and Brennan 1981; Bresnahan et al. 2002; McKenzie 2008; Ahmed, Abdullah and Heng 2014). Others attributed their results to the Accent Prestige Theory, which maintains that people speaking with a standardized accent are awarded higher status than those with a nonstandardized accent (Giles 1970; Fuertes, Potere, and Ramirez 2002). People speaking with the standardized accent were perceived to have higher status (e.g., intelligence and education) and were often perceived positively with respect to solidarity traits (e.g., friendliness, trustworthiness, and kindness). Speakers of standardized and non-standardized accents would perceive people speaking the standardized accent to have higher status, while only people speaking non-standardized accents would perceive non-standardized accents more favourably in terms of solidarity traits (Feurtes et al. 2002). In the same vein, others attributed the negative perceptions of accented speech to the power associated with English-speaking countries (Dragojevic and Goatley-Soan 2020). Familiarity Hypothesis also played a role here (Dalton-Puffer, Kaltenboeck, and Smit 1997), where NNS' judges tended to prefer accents with which they were most familiar. Other researchers (e.g., Hendriks, van Meurs, and Reimer 2018) have attributed this to the difficulties associated with processing FAs, rather than to stereotypes and prejudice against foreigners.

\section{Methodology}

In this section, we first give information on speakers and the tool used to elicit data from them, and then we describe the listener groups who rated the speakers.

\subsection{Speaker Groups}

Three groups of speakers took part in this study: two groups of JA bilinguals ${ }^{1}$ (speaking Arabic and English) with two levels in English and one control group of six male and female NSs (three Americans (two females and one male) and three British (two females and one male); mean age=41.2). The control group was included to provide evaluation criteria for the raters, and more importantly to exclude any unreliable raters who showed discrepancies in their judgments. The first group of bilinguals comprised six JA learners of English (three males and three females; mean age $=20.2$ ). They were all English language major students in

A bilingual in this study refers to any person who speaks two languages regardless of the language level. 
their second year, and their English level can be classified as upper-intermediate: they had been exposed to the language for 12 years in schools (equivalent to intermediate level), and two years at university. Also, their performance in the first two years ranged from good to very good (they were matched for their grade point averages (3-3.5/4). The second group of JA bilinguals was composed of six advanced bilinguals who were teachers of English at schools and tertiary levels with a minimum exposure of 20 years to the language (three males and three females; mean age=36.3). All participants in both groups studied in Arabic-medium schools and none had lived in an English-speaking country. It should be noted that two more participants were recorded for practicing purposes (see below).

\subsection{Materials}

The participants in the three groups were recorded reading Aesop's story 'The North Wind and the Sun' individually at a normal pace in a quiet room by the first researcher. Choosing a story rather than sentences is motivated on the grounds that it is more natural. The story took 40 seconds on average to read, which is more than enough to make a reasonably accurate decision on the accentedness of speech. Flege (1984) found that even 30 milliseconds can be sufficient to judge whether the speech is said by an NS or NNS. The recordings were given numbers from 1 to 18 , randomized and saved on a laptop.

\subsection{Listener Groups/Raters}

Three groups of raters listened to and rated the speech of each reader on four traits: foreign accentedness, clarity and two solidarity traits, namely pleasantness of accent, and friendliness. The raters listened to the speakers one by one individually and were requested to rate the speakers on the 9 -point scale ( $1=$ the best, and $9=$ the worst (see Appendix)). The stimulus was presented to the raters on a laptop in a quiet room and the raters could repeat the recording, if they wanted to.

The first group of listeners $(\mathrm{n}=30 ; 16$ males and 14 females; mean age $=40)$ represented nonspecialist JA bilinguals (non-specialists). All of them held a BA or an MA degree in a major other than English and none of them was a teacher. They used English on a daily basis at their work. The second group ( $\mathrm{n}=30 ; 18$ males and 12 females; mean age $=41)$ represented specialist Jordanian teachers of English (specialists). All of them were teaching English to Arab learners with a minimum of 10 years of experience. All the raters in both groups had been living in the $\mathrm{UAE}$ for a minimum of ten years at the time of data collection. It is worth mentioning that the raters in these two groups grew up in Jordan and moved to the UAE as adults. The third group $(\mathrm{n}=30 ; 17$ males and 13 females; mean age $=42)$ represented experienced American and British English NSs. All of them were teachers of English to Arab learners with a minimum of 10 years of experience teaching in the UAE or Saudi Arabia.

Before the beginning of the actual rating session, each rater had the chance to listen to two JA speakers (one advanced and one upper-intermediate) to practice the rating process. These two ratings were not included in the analysis. Upon completing all the ratings, all the results were fed into an Excel file for further comparisons. A one-way ANOVA test was conducted to see if there were statistically significant differences among the three groups of rates. It should 
be noted that one-way rather than factorial ANOVA was conducted as we were interested in the differences between the three groups of raters only, regardless of gender, educational level, or age. Some comparisons did not meet Levene's Test of Equality of Error, so Games-Howell post-hoc tests were used for all of them. Pearson product-moment correlation coefficient tests were also conducted to find out whether there were statistically significant and meaningful correlations among the four constructs.

\section{Results}

Overall, the results showed that the upper-intermediate participants received a less favourable ${ }^{2}$ evaluation on the four traits than the advanced participants, who in turn received a less positive evaluation than the NSs. The results suggest that the more foreign-accented the speech was, the less favourably it was perceived by all listeners. Furthermore, the higher the English level and more experienced listeners were, the more positive their reactions to the speakers tended to be. It should be noted that we assume that the NS listeners had the highest level in English. In this section, we present the mean ratings of all speakers by the three groups. We then compare the ratings of the three groups and calculate the correlations among the four traits.

\subsection{Listeners' Perceptions of the Three Groups of Speakers}

In this subsection, we summarize how each group of listeners perceived the members of each group of speakers (the upper-intermediate, advanced and English native groups) with respect to FA, friendliness, pleasantness and clarity. It is worth mentioning that the advanced group of JA speakers read the story without mistakes at the segmental and word stress levels, but their performance in terms of sentence stress, rhythm, intonation and tempo was different from that of NSs'. The upper-intermediate JA speakers' performance was less native-like with a few mistakes at the segmental and word stress levels, besides mistakes at the suprasegmental level. Therefore, it is not unexpected that both groups of NNSs, particularly the upper-intermediate group, will have less favourable ratings in terms of FA, especially because suprasegmental aspects play a major role in perceptions of foreign accentedness (Munro and Derwing 1995).

\subsubsection{Perceptions of FA}

In general, JA-accented speech, especially that of the upper-intermediate group, was perceived less favourably than that of the NSs in terms of accentedness while the NSs, as expected, were perceived to speak with no FA. NS judges viewed that both the upperintermediate and advanced speakers spoke with a relatively strong FA (M=7.6 and 6.1, respectively) while they perceived English NSs to speak with no FA $(M=1.1)$. Specialists also perceived JA-accented speech unfavourably. They felt that the upper-intermediate speakers spoke with a very strong FA $(M=7.2)$ and the advanced speakers with a moderate FA $(M=5.3)$. However, they, like the NS listeners, perceived NSs to speak with no FA

\footnotetext{
2 We use the word 'favourable' in two ways here: the first is an objective way to make comparisons between groups while the second is rather subjective, whereby a rating below 3 is favourable whereas a rating above 6 is unfavourable.
} 
$(M=1.2)$. Similarly, non-specialists rated the upper-intermediate participants with a strong FA $(M=6.8)$ and the advanced participants with a moderate FA $(M=5.3)$. They also perceived the NS group as speaking with almost no FA $(M=1.7)$.

TABLE 1. FA perceptions.

\begin{tabular}{|c|c|c|c|c|}
\hline Group & Speaker & NSs' means & $\begin{array}{l}\text { Specialists' } \\
\text { Means }\end{array}$ & $\begin{array}{c}\text { Non-Specialists' } \\
\text { Means }\end{array}$ \\
\hline \multirow{7}{*}{ Upper-Intermediate } & 1 & 7.3 & 6.6 & 6.5 \\
\hline & 2 & 7 & 6.9 & 6.4 \\
\hline & 3 & 8.3 & 7.7 & 6.9 \\
\hline & 4 & 7.6 & 7.9 & 7.7 \\
\hline & 5 & 7 & 6.4 & 6.1 \\
\hline & 6 & 8 & 7.6 & 7.4 \\
\hline & Average & 7.6 & 7.2 & 6.8 \\
\hline \multicolumn{2}{|l|}{ Overall Average } & \multicolumn{3}{|c|}{7.2} \\
\hline \multirow[t]{7}{*}{ Advanced } & 7 & 7 & 6.1 & 6.6 \\
\hline & 8 & 5 & 3.6 & 4.1 \\
\hline & 9 & 5.3 & 6 & 5.8 \\
\hline & 10 & 5.7 & 5.3 & 5.4 \\
\hline & 11 & 6.3 & 5.8 & 6 \\
\hline & 12 & 7 & 5.2 & 4 \\
\hline & Average & 6.1 & 5.3 & 5.3 \\
\hline \multicolumn{2}{|l|}{ Overall Average } & \multicolumn{3}{|c|}{5.6} \\
\hline \multicolumn{2}{|l|}{ All NNSs } & \multicolumn{3}{|c|}{6.4} \\
\hline \multirow[t]{7}{*}{$\mathrm{NSs}$} & 13 & 1 & 1.1 & 1.6 \\
\hline & 14 & 1 & 1.7 & 2.3 \\
\hline & 15 & 1 & 1.1 & 1.3 \\
\hline & 16 & 1 & 1 & 1.7 \\
\hline & 17 & 1 & 1 & 1.3 \\
\hline & 18 & 1.3 & 1 & 1.7 \\
\hline & Average & 1.1 & 1.2 & 1.7 \\
\hline \multicolumn{2}{|l|}{ Overall Average } & \multicolumn{3}{|c|}{1.3} \\
\hline
\end{tabular}

Overall, English NSs were perceived to speak with no FA by the three groups of raters, while both groups of JA bilinguals were perceived to speak with a moderate to strong FA by all groups.

\subsubsection{Perceptions of Friendliness}

Unlike the perceptions of FA, the NSs' group reacted more favourably toward the three groups in terms of friendliness. NSs perceived upper-intermediate and advanced speakers to be quite friendly ( $\mathrm{M}=3$ and 2.2 , respectively) and the native speaker group slightly more friendly $(\mathrm{M}=1.9)$. 
Specialists and non-specialists had similar trends. They reacted less favourably than the NS judges perceiving the upper-intermediate and the advanced groups to be moderately friendly (means around 5). However, both perceived NSs to be more friendly than JA-accented speakers, with a mean around 2. Details are given in Table 2.

TABLE 2. Perceptions of friendliness.

\begin{tabular}{|c|c|c|c|c|}
\hline Group & Speaker & NSs' Means & $\begin{array}{c}\text { Specialists' } \\
\text { Means }\end{array}$ & $\begin{array}{c}\text { Non-Specialists' } \\
\text { Means } \\
\end{array}$ \\
\hline \multirow[t]{8}{*}{$\begin{array}{l}\text { Upper- } \\
\text { Intermediate } \\
\end{array}$} & 1 & 3.3 & 4.7 & 4.9 \\
\hline & 2 & 3.7 & 5.3 & 5.2 \\
\hline & 3 & 2 & 5.6 & 5 \\
\hline & 4 & 4 & 6.2 & 6.4 \\
\hline & 5 & 3 & 4.8 & 4.5 \\
\hline & 6 & 1.7 & 5.2 & 5.3 \\
\hline & Average & 3.0 & 5.3 & 5.2 \\
\hline & Overall Average & & 4.6 & \\
\hline \multirow[t]{8}{*}{\begin{tabular}{|l|} 
Advanced \\
\end{tabular}} & 7 & 2 & 5.5 & 5.9 \\
\hline & 8 & 2 & 3.4 & 4 \\
\hline & 9 & 2 & 3.9 & 4.1 \\
\hline & 10 & 2.3 & 4.3 & 3.9 \\
\hline & 11 & 2.7 & 4.4 & 4.9 \\
\hline & 12 & 2.3 & 3.9 & 4.1 \\
\hline & Average & 2.2 & 4.2 & 4.5 \\
\hline & Overall Average & \multicolumn{3}{|c|}{3.6} \\
\hline All NNSs & & \multicolumn{3}{|c|}{4.1} \\
\hline \multirow[t]{8}{*}{ NSs } & 13 & 3 & 2.7 & 2 \\
\hline & 14 & 1.7 & 2.6 & 2.7 \\
\hline & 15 & 2 & 1.6 & 1.7 \\
\hline & 16 & 1.3 & 1.3 & 2.1 \\
\hline & 17 & 1.3 & 1.4 & 2 \\
\hline & 18 & 2 & 1.8 & 2.5 \\
\hline & Average & 1.9 & 1.9 & 2.2 \\
\hline & Overall Average & \multicolumn{3}{|c|}{2.0} \\
\hline
\end{tabular}

Overall, the lower the level in English, the less friendly a speaker was perceived, especially among the NNS raters. NNSs reacted less favourably than the NSs toward the upperintermediate and advanced participants.

\subsubsection{Perceptions of Pleasantness}

The results for pleasantness, which is again a very subjective trait, were like those for friendliness, as shown in Table 3 below. JA-accented speech was perceived to be moderately 
pleasant $(M=4.3)$ while the NSs were perceived to be more pleasant $(M=2)$. NSs perceived JA-accented speech to be more pleasant than did the two groups of JA judges. However, NSs perceived the upper-intermediates to be less pleasant $(\mathrm{M}=3.2)$ than the advanced group $(\mathrm{M}=2.4)$. They perceived the NS group to be the most pleasant $(\mathrm{M}=2.2)$, a mean that is very close to that of the advanced participants.

Specialists were less tolerant than the NSs toward JA-accented speech, especially toward the upper-intermediates $(\mathrm{M}=6)$. They perceived the NSs more positively than the NSs perceived other NSs $(M=1.7)$. Non-specialists followed the same pattern. They were less favourably inclined toward the upper-intermediate $(M=5.3)$ and advanced $(M=4.5)$ speakers, while they perceived the NSs to be very pleasant $(\mathrm{M}=2.2)$.

TABLE 3. Perceptions of pleasantness.

\begin{tabular}{|c|c|c|c|c|}
\hline Group & Speaker & NSs' Means & $\begin{array}{c}\text { Specialists' } \\
\text { Means } \\
\end{array}$ & \begin{tabular}{|c}
$\begin{array}{c}\text { Non-Specialists' } \\
\text { Means }\end{array}$ \\
\end{tabular} \\
\hline \multirow[t]{8}{*}{$\begin{array}{l}\text { Upper } \\
\text { Intermediate }\end{array}$} & 1 & 3 & 5.3 & 4.7 \\
\hline & 2 & 4 & 5.9 & 5 \\
\hline & 3 & 2.7 & 6 & 5.3 \\
\hline & 4 & 4 & 6.8 & 6.6 \\
\hline & 5 & 2.7 & 5.4 & 4.6 \\
\hline & 6 & 2.7 & 6.6 & 5.3 \\
\hline & Average & 3.2 & 6.0 & 5.3 \\
\hline & Overall Average & \multicolumn{3}{|c|}{4.8} \\
\hline \multirow[t]{8}{*}{ Advanced } & 7 & 1.7 & 5.2 & 5.9 \\
\hline & 8 & 2 & 3.2 & 3.9 \\
\hline & 9 & 2 & 4.1 & 4.1 \\
\hline & 10 & 3 & 4.6 & 4 \\
\hline & 11 & 2.3 & 4 & 4.5 \\
\hline & 12 & 3.3 & 4.7 & 4.4 \\
\hline & Average & 2.4 & 4.3 & 4.5 \\
\hline & Overall Average & \multicolumn{3}{|c|}{3.7} \\
\hline All NNSs & & \multicolumn{3}{|c|}{4.3} \\
\hline \multirow[t]{8}{*}{ NSs } & 13 & 2.3 & 2 & 2.5 \\
\hline & 14 & 2 & 2.6 & 2.3 \\
\hline & 15 & 2.3 & 1.4 & 1.6 \\
\hline & 16 & 2.3 & 1.4 & 2 \\
\hline & 17 & 1.3 & 1.1 & 2 \\
\hline & 18 & 3 & 1.6 & 2.7 \\
\hline & Average & 2.2 & 1.7 & 2.2 \\
\hline & Overall Average & \multicolumn{3}{|c|}{2.0} \\
\hline
\end{tabular}




\subsubsection{Perceptions of Clarity}

As is clear from Table 4, the upper-intermediates were perceived to be less clear $(M=5.2)$ than the advanced speakers $(M=3.5)$, who were perceived to be less clear than the NSs $(M=1.4)$. The NSs had more favourable perceptions of the upper-intermediates $(M=4.3)$ and the advanced speakers $(M=2.7)$, and reacted in a similar fashion to specialists toward other NSs $(M=1.1)$. Specialists felt the upper-intermediate participants to be less clear than the advanced speakers $(M=3.5)$, but perceived the NSs to be the clearest $(M=1.1)$. Nonspecialists behaved similarly to specialists but were less favourably inclined in general toward the other groups. They perceived the upper-intermediates to be less clear than the advanced and NS groups ( $M=5.8,4.3$ and 2, respectively).

TABLE 4. Perceptions of clarity.

\begin{tabular}{|c|c|c|c|c|}
\hline Group & Speaker & NSs' Means & $\begin{array}{c}\text { Specialists' } \\
\text { Means } \\
\end{array}$ & $\begin{array}{c}\text { Non-Specialists' } \\
\text { Means } \\
\end{array}$ \\
\hline \multirow[t]{8}{*}{ Upper-Intermediate } & 1 & 3.7 & 4.3 & 5.5 \\
\hline & 2 & 4.3 & 4.9 & 4.9 \\
\hline & 3 & 5.7 & 5.8 & 6.4 \\
\hline & 4 & 4.3 & 5.6 & 6.7 \\
\hline & 5 & 3.3 & 4.8 & 4.5 \\
\hline & 6 & 4.7 & 6.4 & 6.9 \\
\hline & Average & 4.3 & 5.3 & 5.8 \\
\hline & Overall Average & \multicolumn{3}{|c|}{5.2} \\
\hline \multirow[t]{8}{*}{ Advanced } & 7 & 2.7 & 3.7 & 5.1 \\
\hline & 8 & 2 & 2.2 & 3.9 \\
\hline & 9 & 3 & 3.9 & 4.6 \\
\hline & 10 & 2.7 & 3.8 & 3.7 \\
\hline & 11 & 3.3 & 4 & 4.9 \\
\hline & 12 & 2.7 & 3.4 & 3.7 \\
\hline & Average & 2.7 & 3.5 & 4.3 \\
\hline & Overall Average & \multicolumn{3}{|c|}{3.5} \\
\hline All NNSs & & \multicolumn{3}{|c|}{4.3} \\
\hline \multirow[t]{8}{*}{ NSs } & 13 & 1 & 1 & 1.9 \\
\hline & 14 & 1 & 1.3 & 2 \\
\hline & 15 & 1 & 1.2 & 1.7 \\
\hline & 16 & 1.3 & 1.1 & 1.8 \\
\hline & 17 & 1 & 1 & 2 \\
\hline & 18 & 1 & 1 & 2.5 \\
\hline & Average & 1.1 & 1.1 & 2.0 \\
\hline & Overall Average & \multicolumn{3}{|c|}{1.4} \\
\hline
\end{tabular}


Again, perceptions of clarity seem to be correlated with the level of English - the higher the level, the clearer the participant is felt to be.

To summarize this section, the upper-intermediates were perceived to be more foreignaccented, less friendly, less pleasant and less clear than the advanced participants who in turn were perceived less favourably on the four constructs than the NSs, an indication that the higher their level in English, the more favourably a speaker tends to be perceived. NSs' judgments of all attributes except for FA were generally more favourable than those of specialists, whose ratings were more favourable than those of non-specialists. A one-way ANOVA was conducted to see whether there were any statistically significant differences among the three groups.

\subsection{Differences among the Groups of Listeners}

We conducted ANOVA tests of the judges' ratings of each group (upper-intermediate, advanced and NS, each on its own) and then performed an ANOVA tests of all of them. This is necessary to see if there were statistically significant differences between the evaluations of the smaller groups, as taking all the ratings of all groups will make the data set very large and may not give a clear picture of actual differences.

The results of the ANOVA tests revealed that there were generally clear differences between the NS judges on the one hand and the two NNS groups on the other, with negligible differences between the two NNS groups.

The differences in FA ratings of the upper-intermediate group were statistically significant $(\mathrm{F}(2,537)=17.787, \mathrm{p}=.001$, eta-squared $=.062)$. Post-hoc Games-Howell tests revealed statistical differences between the three groups at a .05 alpha level. However, the effect size was very low, meaning that these differences were not meaningful or practical. Concerning the advanced group's ratings of FA, the results showed that there were statistically significant differences between the NSs and both specialists and non-specialists, but no differences between non-specialists and specialists. Games-Howell post-hoc results were .997 for specialists vs. non-specialists, and .001 for the other groups. Effect size was also very small (eta-squared=.039). Regarding the evaluations of the NS group, there were statistically significant differences between all groups although to a lower degree between specialists vs. NSs ( $\mathrm{p}=.026)$. The effect size was higher but again relatively small (eta-squared=.14). Taking all ratings of FA made by the three groups together, we found statistically significant differences only between non-specialists and NSs ( $\mathrm{p}=.009)$.

With respect to friendliness, pleasantness and clarity, differences with larger size effects were found among the three groups. In general, there were clear differences between the native raters on the one hand and the other two groups of NNSs on the other. This is evident from the mean ratings of each group, with the NNS groups having more similar means. This means that the NS judges (with a mean lower than 2.8 for the three traits compared with a mean around 4 for the other groups) had significantly more positive attitudes than the NNSs. 
To summarize this section, the upper-intermediate speakers were perceived unfavourably with respect to FA. The three groups of raters, especially the NSs, perceived them to speak with a very strong accent $(M=7.2)$. With respect to the other traits, the upper-intermediates were perceived to be moderately friendly, pleasant and clear (4.6-5.2). In contrast, the advanced speakers were perceived to have a less strong FA than the upper-intermediate bilinguals; however, they were still perceived to speak with a relatively strong FA ( $M=5.6)$. For the other traits, they were more positively perceived, especially by the NS group. These ratings suggest that a stronger FA plays a clear role in the way the speakers are perceived with respect to the other traits (see details below). In sharp contrast to the JA bilinguals, the NSs were perceived favourably by the three groups of listeners. As expected, they were perceived to speak without an FA, and this seems to affect the way they were perceived in terms of friendliness, pleasantness and clarity ( $M=1.3$ to 2$)$.

Concerning the perceptions of the three groups of raters, clear differences were found between the NS raters on the one hand and the two groups of the JA bilinguals on the other, with fewer differences with respect to FA. Both specialist and non-specialist JA judges perceived their compatriots less favourably (except for FA) than the NS raters did. The upperintermediate and advanced bilinguals were perceived by the JA listeners to be less friendly, less pleasant and less clear. As for the NS group, they were perceived in a similar fashion by the English NS raters and JA raters.

These results seem to suggest that JA specialist and non-specialist raters link the degree of foreign accentedness and the other traits. To find out whether this is the case, we conducted Pearson product-moment correlation coefficient tests among the four traits. A strong positive correlation was found among the four traits with the JA raters; however, a strong positive correlation was found only between the three traits (friendliness, pleasantness and clarity) but not FA with the NS raters. The table below presents the correlations among all traits.

TABLE 5. Correlations among the three groups of judges.

\begin{tabular}{|c|c|c|c|c|}
\hline & FA & Friendliness & Pleasantness & Clarity \\
\hline \multicolumn{5}{|c|}{ Non-Specialist Judges } \\
\hline FA & & $.73^{* *}$ & $.70^{* *}$ & $.80^{* *}$ \\
\hline Friendliness & & & $.90^{* *}$ & $.76^{* *}$ \\
\hline Pleasantness & & & & $.78^{* *}$ \\
\hline \multicolumn{5}{|c|}{ Specialist Judges } \\
\hline FA & & $.65^{* *}$ & $.75^{* *}$ & $.76^{* *}$ \\
\hline Friendliness & & & $.90^{* *}$ & $.86^{* *}$ \\
\hline Pleasantness & & & & $.85^{* *}$ \\
\hline
\end{tabular}




\begin{tabular}{|l|l|l|l|l|}
\hline \multicolumn{5}{|l|}{ NS Judges } \\
\hline FA & & $.29^{* *}$ & $.33^{* *}$ & $.74^{* *}$ \\
\hline Friendliness & & & $.66^{* *}$ & $.48^{* *}$ \\
\hline Pleasantness & & & & $.53^{* *}$ \\
\hline
\end{tabular}

(at .001 level)

As is clear from Table 5, all correlations among the four attributes for the non-specialist and the specialist raters were very strong. However, correlations between FA and other attributes (except FA and clarity) among the NS raters were weak. NSs had stronger correlations between the other three traits, but these correlations were still weaker than those found among the NNS raters.

\section{Discussion and Conclusion}

The primary aim of the present study was to explore the reactions of English NSs and JA bilinguals toward JA-accented English. We found that JA-accented speech, unlike English native speech, was perceived less favourably, especially by JA bilinguals. JA-accented speech was perceived to have a relatively strong FA by all groups of raters. JA-accented speech was also perceived to be less friendly, less pleasant and less clear than that of native speakers, with the upper-intermediate group having less positive reactions than the advanced group. This suggests that listeners are able to differentiate degrees of accentedness, as the upperintermediate group was less native-like than the advanced group.

Statistically significant differences were found between the ratings made by the NS judges and the two groups of NNS judges with respect to all attributes. Small differences were established between the non-specialist and specialist judges, with the non-specialists being less tolerant than the specialists. This shows that the level and knowledge of the English language seem to affect the judges' perceptions. The higher the level is, the more tolerant the judge is. One possible explanation for this is that the non-specialists do not seem to have the knowledge and expertise required to understand the complicated process of acquiring foreign language pronunciation. In contrast, the more positive attitudes of NSs toward JAaccented speech may be attributed to the fact that all the NSs were teachers of English in the UAE or Saudi Arabia, and their experience with NNSs could have made them more tolerant of foreign accentedness. These findings are in agreement with many earlier studies which found that stronger FAs were perceived more negatively than slight FAs (e.g., Dalton-Puffer, Kaltenboeck, and Smit 1997 for Austrian speakers; Cargile and Giles 1998 for Japanese speakers; Nejjari et al. 2012 for Dutch speakers; Dragojevic et al. 2017 for Mandarin and Punjabi speakers; Hendriks, van Meurs and Reimer 2018 for Dutch and German speakers).

On the other hand, the most counter-intuitive finding in the present study is the fact that the JA bilinguals were less favourable in their ratings of JA-accented speech than were the NSs with respect to solidarity attributes. These findings contradict other studies such as Ahmed, Abdullah and Heng (2014) and Lin et al. (2018), which found that EFL students did not 
show preferences toward native English accents. These findings go against the Familiarity Hypothesis, whereby being used to the accented speech induces positive reactions among the same group participants as a type of in-group marker. These findings also contradict Perceived Similarity Theory (Tims and Miller 1986), which claims that perceived similarity among participants positively affects attitudes toward members belonging to the same group. Although the JA judges were expected to be familiar and used to the JA-accented speech of their compatriots, they still perceived it less favourably.

These results are also contrary to other studies such as Brennan and Brennan (1981), Said (2006) and McKenzie (2008), which reported that NNSs perceived non-native accents more favourably than did NSs, especially with respect to solidarity. In the current work the JA judges rated their compatriots less favourably than the English NSs on friendliness and pleasantness. One possible reason for these less favourable reactions is that JA judges regard native English accents as the norm, and expect NNSs of English to speak without a foreign accent. This suggests that an English native accent is admired and attitudes toward native English accents are positive. These findings are in harmony with the Accent Prestige Theory, whereby standardized accents are perceived more favourably than non-standardized ones (Fuertes, Potere, and Ramirez 2002).

The substantial correlations between the four attributes with a correlation coefficient magnitude of no less than .65 among the NNS raters suggest that the raters overgeneralize their judgments. They tend to equate FA with other attributes such that the more accented the speech is, the less friendly, less pleasant and less clear a speaker is perceived to be. This shows that there seems to be a close association between English proficiency and raters' evaluations, such that the higher the level in English, the more positive the reactions are, with the NS group receiving the most favourable evaluations followed by the advanced and the upperintermediate groups. These results are not unexpected for FA and clarity on the one hand, and pleasantness and friendliness on the other, as these attributes are highly interrelated and could be seen to measure the same general attribute, while they are unpredicted for the other attributes as there is no logical relationship between them. The results of this study suggest that reactions to foreign-accented speech are not only based on linguistic qualities (as evident from the ratings of the advanced JA speakers compared to the upper-intermediate speakers, whose level of English is lower than that of the advanced speakers), but they seem to be based on inherent preferences that play a major role in shaping stereotypes with considerable (sometimes negative) consequences. Bias against NNSs is clear from the advanced speakers' ratings, which were significantly lower than those of NSs, although the advanced speakers did not make mistakes at the segmental and word levels.

Despite the highly multilingual and ethnically diverse environment where all the raters live, the degree of FA was found to strongly affect the perceptions of the other attributes, especially among the NNS judges. It was expected that in such environments people would be less bothered by foreign accentedness, especially that of their own compatriots (Kraut and Wulff 2013). This seems to suggest that reactions to FA take shape quite early in people's lives, as all the raters in the two NNS groups grew up in Jordan, whose community is less diverse ethnically and linguistically than that of the UAE (Abu Guba 2016). 


\subsection{Implications}

Although achieving a native-like accent is admirable, the degree of FA should not affect the judgments of speakers' competence and solidarity attributes, especially because it is almost impossible for late learners of a foreign language to achieve a native-like accent, regardless of their abilities (cf. Celce-Murcia, Brinton and Goodwin 2010). Prejudices against FAs should be eliminated and people, especially L2 learners, should be aware of the existence of such negative reactions to foreign-accented speech. An intelligible accent should be the norm, without insisting on a native-like accent (cf. Lindemann, Litzenberg and Subtirelu 2014,189), and non-native accents should be viewed as a natural by-product of learning a foreign language.

These findings should help L1 and especially L2 speakers reconsider their attitudes toward foreign-accented speech, as a greater awareness might help in reducing prejudices against such speech (Carlson and McHenry 2006; Roessel et al. 2019). In this regard, Roessel et al. (2019) demonstrated that raising awareness of such prejudices helps in reducing negative reactions toward non-native accents. Said (2006) showed that raters judged foreign-accented speech more favourably when they were given more chance to reflect upon their decisions. Therefore, it can be expected that more exposure to accents and raising awareness of the natural diversity of accents would lead to more positive attitudes toward FAs.

Nevertheless, L2 speakers need to be aware of the existence of such prejudices against their foreign-accented speech. The finding that the two NNS groups of listeners were aware of and sensitive to the presence of an FA, especially among the advanced participants, necessitates that NNS should try to eliminate foreign linguistic features that affect their speech negatively, especially suprasegmental features, which play a major role in FAs (Munro and Derwing 1995). This does not mean they must achieve a native-like accent, but instead they should try to eliminate a strong FA as much as possible due to the negative prejudices against FAs. This is especially required from advanced speakers of English, in particular those who intend to teach the language.

\subsection{Limitations and Suggestions for Further Research}

The number of listeners and speakers in the three groups in this study were relatively small, and it was not possible to match all the speakers for age. This might have affected the results negatively, and therefore a future study with a larger number of speakers belonging to the same age group would lend support to the findings of our exploratory study. Moreover, this paper focused on the perception of foreign-accented speech with respect to solidarity traits. As such, it remains to be discovered whether listeners link FA with other traits that are more independent of FA than those we explored in this study. Future studies that measure the correlation between accentedness and perceptions of competence traits such as intelligence and confidence would be highly recommended. Moreover, future studies that recruit both experienced and non-linguistically trained English NS listeners rating Arabic and other nonnative-accented English might reveal interesting results that enable us to better understand reactions to Arabic-accented English. 


\section{Acknowledgements}

We would like to express our gratitude to the anonymous reviewers for their careful review and insightful comments. Thanks are to the participants for their valuable time and efforts. Thanks are also due to Nour Abu Guba for his assistance with the data.

\section{References}

Abu Guba, Mohammed Nour. 2016. "Phonological Adaptation of English Loanwords in Ammani Arabic.” PhD Diss., Salford University.

Ahmed, Zainab Thamer, Ain Nadzimah Abdullah, and Chan Swee Heng S. 2014. "Malaysian University Students' Attitudes Towards Six Varieties of Accented Speech in English." Advances in Language and Literary Studies 5 (5): 181-91. https://doi.org/10.7575/aiac.alls.v.5n.5p.181.

Anderson-Hsieh, Janet, and Kenneth Koehler. 1988. "The Effect of Foreign Accent and Speaking Rate on Native Speaker Comprehension.” Language Learning 38 (4): 561-13. https:// doi.org/10.1111/j.1467-1770.1988.tb00167.x.

Brennan, Eileen M., and John S. Brennan. 1981. "Accent Scaling and Language Attitudes: Reactions to Mexican American English Speech.” Language and Speech 24 (3): 207-21. https://doi.org/10.1177 /002383098102400301.

Bresnahan, Mary Jiang, Rie Ohashi, Reiko Nebashi, Wen Ying Liu, and Sachiyo Morinaga Shearman. 2002. "Attitudinal and Affective Response Toward Accented English." Language and Communication 22 (2): 171-85. https://doi.org/10.1016/S0271-5309(01)00025-8.

Cargile, Aaron Castelan, and Howard Giles. 1998. "Language Attitudes toward Varieties of English: An American-Japanese Context." Journal of Applied Communication Research 26 (3): 338-56. https:// doi.org/10.1080/00909889809365511.

Cargile, Aaron Castelan, Eriko Maeda, Jose Rodriguez, and Marc Rich. 2010. “'Oh, You Speak English So Well!' US American Listeners' Perceptions of 'Foreignness' among Nonnative Speakers.” Journal of Asian American Studies 13 (1): 59-79. https://doi.org/10.1353/jaas.0.0062.

Carlson, Holly K., and Monica A. McHenry. 2006. "Effect of Accent and Dialect on Employability.” Journal of Employment Counseling 43 (2): 70-83. https:// doi.org/10.1002/j.2161-1920.2006.tb00008.x.

Celce-Murcia, Marianne, Donna M. Brinton, and Janet M. Goodwin. 2010. Teaching Pronunciation Hardback with Audio Cds (2): A Course Book and Reference Guide. Cambridge: Cambridge University Press.

Chiba, Reiko, Hiroko Matsuura, and Asako Yamamoto. 1995. "Japanese Attitudes toward English Accents." World Englishes 14 (1): 77-86. https://doi.org/10.1111/j.1467-971X.1995.tb00341.x.

Coupland, Nikolas, and Hywel Bishop. 2007. "Ideologised Values for British Accents." Journal of Sociolinguistics 11: 74-93. https://doi.org/10.1111/j.1467-9841.2007.00311.x.

Dalton-Puffer, Christiane, Gunther Kaltenboeck, and Ute Smit. 1997. "Learner Attitudes and L2 Pronunciation in Austria." World Englishes 16 (1): 115-28. https://doi.org/10.1111/1467971X.00052/.

Deprez-Sims, Anne-Sophie, and Scott B. Morris. 2010. "Accents in the Workplace: Their Effects during a Job Interview." International Journal of Psychology 45 (6): 417-26. https:// doi.org/10.1080/00207594.2010.499950.

Deterding, David, and Andy Kirkpatrick. 2006. "Emerging South-East Asian Englishes and Intelligibility." World Englishes 25 (3-4): 391-409. https://doi.org/10.1111/j.1467-971X.2006.00478.x.

Dragojevic, Marko, and Sean Goatley-Soan. 2020. "Americans' Attitudes toward Foreign Accents: Evaluative Hierarchies and Underlying Processes." Journal of Multilingual and Multicultural Development. 1-15. https://doi.org/10.1080/01434632.2020.1735402.

Dragojevic, Marko, Howard Giles, Anna-Carrie Beck, and Nicholas T. Tatum. 2017. "The Fluency Principle: Why Foreign Accent Strength Negatively Biases Language Attitudes.” Communication Monographs 84 (3): 385-405. https://doi.org/10.1080/03637751.2017.1322213. 
Eisenhower, Kristina. 2002. "American Attitudes toward Accented English.” MA thesis, McGill University, Montreal.

Flege, James Emil. 1984. “The Detection of French Accent by American Listeners.” The Journal of Acoustical Society of America 76: 692-707. https://doi.org/10.1121/1.391256.

Friedrich, Patricia. 2000. "English in Brazil: Functions and Attitudes." World Englishes 19 (2): 215-23. https://doi.org/10.1111/1467-971X.00170.Frumkin, Lara. 2007. "Influences of Accent and Ethnic Background on Perceptions of Eyewitness Testimony." Psychology, Crime and Law 13 (3): 317-31. https://doi.org/10.1080/10683160600822246.

Fuertes, Jairo N., Jodi C. Potere, and Karen Y. Ramirez. 2002. "Effects of Speech Accents on Interpersonal Evaluations: Implications for Counseling Practice and Research." Cultural Diversity and Ethnic Minority Psychology 8 (4): 346-56. https://psycnet.apa.org/doi/10.1037/1099-9809.8.4.347.

Garrett, Peter. 2010. Attitudes to Language. Cambridge: Cambridge University Press.

Giles, Howard. 1970. "Evaluative Reactions to Accents." Educational Review 22 (3): 211-27. https:// doi.org/10.1080/0013191700220301.

Giles, Howard, Miles Hewstone, Ellen B. Ryan, and Patricia Johnson. 1987. "Research on Language Attitudes.” In Sociolinguistics, edited by H. Ammon, N. Dittmmar, and J. K. Mattheier, 585-97. Berlin: Walter de Gruyter.

Gill, Mary M. 1994. "Accent and Stereotypes: Their Effect on Perceptions of Teachers and Lecture Comprehension." Journal of Applied Communication Research 22 (4): 348-61. https://doi.org/10.1080 100909889409365409.

Gluszek, Agata, and John F. Dovidio. 2010. "The Way They Speak: A Social Psychological Perspective on the Stigma of Nonnative Accents in Communication." Personality and Social Psychology Review 14 (2): 214-37. https://doi.org/10.1177\%2F1088868309359288.

Hendriks, Berna, Frank van Meurs, and Ann-Katrin Reimer. 2018. "The Evaluation of Lecturers' Nonnative-Accented English: Dutch and German Students' Evaluations of Different Degrees of Dutch-Accented and German-Accented English of Lecturers in Higher Education." Journal of English for Academic Purposes 34: 28-45. https://doi.org/10.1016/j.jeap.2018.03.001.

Jenkins, Jennifer. 2007. English as a Lingua Franca: Attitude and Identity. Oxford: Oxford University Press.

Kraut, Rachel, and Stefanie Wulff. 2013. "Foreign-Accented Speech Perception Ratings: A Multifactorial Case Study." Journal of Multilingual and Multicultural Development 34 (3): 249-63. https:// doi.org/10.1080/01434632.2013.767340.

Lambert, Wallace E., Hannah Frankle, and G. Richard Tucker. 1966. “Judging Personality Through Speech: A French-Canadian Example.” Journal of Communication 16 (4): 305-21. https:// doi.org/10.1111/j.1460-2466.1966.tb00044.x.

Lin, Debbita Tan Ai, Lee Bee Choo, Shaidatul Akma Adi Kasuma, and Malini Ganapathy. 2018. "Like That Lah: Malaysian Undergraduates' Attitudes towards Localised English.” GEMA Online Journal of Language Studies 18 (2): 80-92. https://doi.org/10.17576/gema-2018-1802-06.

Lindemann, Stephanie. 2005. "Who Speaks 'Broken English'? U.S. Undergraduates' Perception of Non-Native English." International Journal of Applied Linguistics 15 (2): 187-212. https:// psycnet.apa.org/doi/10.1111/j.1473-4192.2005.00087.x.

Lindemann, Stephanie, Jason Litzenberg, and Nicholas Subtirelu. 2014. "Problematizing the Dependence on L1 Norms in Pronunciation Teaching: Attitudes toward Second Language Accents." In Social Dynamics in Second Language Accent, edited by J. Levis, and A. Moyer, 171-94. Boston/Berlin: De Gruyter.

Lippi-Green, Rosina. 1994. "Accent, Standard Language Ideology, and Discriminatory Pretext in the Courts.” Language in Society 23 (2): 163-98. https://www.jstor.org/stable/4168513.

McKenzie, Robert M. 2008. "Social Factors and Non-Native Attitudes towards Varieties of Spoken English: A Japanese Case Study.” International Journal of Applied Linguistics 18 (1): 63-88. https:// doi.org/10.1111/j.1473-4192.2008.00179.x.

Munro, Murray J., and Tracey M. Derwing 1995. "Processing Time, Accent and Comprehensibility in the Perception of Native and Foreign-Accented Speech.” Language and Speech 38 (3): 289-306. https:// doi.org/10.1177/002383099503800305. 
—. 2001. "Modeling Perceptions of Accentedness and Comprehensibility of L2 Speech." Studies in Second Language Acquisition 23 (4): 451-68. https://doi.org/10.1017/S0272263101004016.

Nejjari, Warda, Marinel Gerritsen, Monique Van der Haagen, and Hubert Korzilius. 2012. "Responses to Dutch-Accented English.” World Englishes 31 (2): 248-67. https://doi.org/10.1111/j.1467971X.2012.01754.x.

Nguyen, Anh-Thu Thi, and John Ingram. 2016. "Vietnamese Accented English: Foreign Accent and Intelligibility Judgement by Listeners of Different Language Backgrounds." English as an International Language Journal 11 (1): 19-38.

Riney, Timothy J., Mari Takada, and Mitsuhiko Ota. 2000. "Segmentals and Global Foreign Accent: The Japanese Flap in EFL.” TESOL Quarterly 34 (4): 711-37. https://doi.org/10.2307/3587782.

Roessel, Janin, Christiane Schoel, Renate Zimmermann, and Dagmar Stahlberg. 2019. "Shedding New Light on the Evaluation of Accented Speakers: Basic Mechanisms Behind Nonnative Listeners' Evaluations of Nonnative Accented Job Candidates." Journal of Language and Social Psychology 38 (1): 3-32. https://doi.org/10.1177\%2F0261927X17747904.

Rounds, Patricia. 1987. "Characterizing Successful Classroom Discourse for Non-Native Teaching Assistant Training." TESOL Quarterly 21: 643-71.

Rubin, Donald L., and Kim A. Smith. 1990. "Effects of Accent, Ethnicity, and Lecture Topic on Undergraduates' Perceptions of Non-Native English-Speaking Teaching Assistants." International Journal of Intercultural Relations 14 (3): 337-53.

Ryan, Ellen Bouchard. 1983. "Social Psychological Mechanisms Underlying Native Speaker Reactions to Nonnative Speech.” Studies in Second Language Acquisition 5 (2):148-59. https://doi.org/10.1017 IS0272263100004824.

Said, Selim Ben. 2006. "Attitudes towards Accented Speech: A Comparative Study of Native and Nonnative Speakers of American English.” MA thesis, Southern Illinois University at Carbondale.

Seidlhofer, Barbara. 2001. "Closing a Conceptual Gap: The Case for a Description of English as a Lingua Franca." International Journal of Applied Linguistics 11 (2): 133-58. https://doi.org/10.1111/14734192.00011.

Tajfel, Henri, and John C. Turner. 1986. "The Social Identity Theory of Intergroup Behavior." In Psychology of Intergroup Relations, edited by S. Worchel and W. G. Austin, 7-24. Chicago: NelsonHall.

Tims, Albert R., and M. Mark Miller. 1986. "Determinants of Attitudes toward Foreign Countries." International Journal of Intercultural Relations 10: 471-84. https://doi.org/10.1016/01471767(86)90046-5.

Watanabe, Yutai. 2008. "New Zealand Attitudes towards Foreign-Accented English." Reo Te 51: 99-127.

Yeni-Komshian, Grace H., James E. Flege, and Serena Liu. 2000. "Pronunciation Proficiency in the First and Second Languages of Korean-English Bilinguals." Bilingualism: Language and Cognition 3 (2): 131-49. https://doi.org/10.1017/S1366728900000225. 


\section{Appendix: The Rating Form}

Directions to raters

Accentedness refers to how strong a speaker's foreign accent is perceived to be.

Please listen to each speaker and rate the speaker for degree of foreign accent, by writing a number from 1 to 9. 1=No foreign accent (native-like) and 9=Very strong foreign accent.

More specifically, ' 1 ' means the speaker sounds like a native speaker of English and ' 9 ' sounds like a non-native speaker with a very strong foreign accent. It would be helpful if you think of a category where a speaker fits and then within each category select the best descriptor.

Good accent: 1, 2, 3 (1=native-like, $2=$ near-native, and, 3 =very mild foreign accent)

Moderate foreign accent: 4, 5, 6 (4=mild foreign accent, 5=slightly moderate foreign accent, $6=$ moderate foreign accent)

Strong foreign accent: 7, 8, 9 (7=a slightly strong foreign accent, 8=a strong foreign accent, and $9=$ a very strong foreign accent)

The same applies to the other traits. Friendliness refers to how the accent is felt to be in terms of kindness and agreeableness, as opposed to hostility or aggressiveness. Pleasantness here relates to how charming and musical/melodious the accent is felt to be. Clarity refers to how clear and easy to understand an accent is felt to be.

\begin{tabular}{|l|l|l|l|l|l|}
\hline Speaker & $\begin{array}{l}\text { Foreign } \\
\text { accent rating } \\
(1-9)\end{array}$ & $\begin{array}{l}\text { Friendliness } \\
\text { rating (1-9) }\end{array}$ & $\begin{array}{l}\text { Pleasantness } \\
\text { rating (1-9) }\end{array}$ & $\begin{array}{l}\text { Clarity rating } \\
(1-9)\end{array}$ & Comments \\
\hline 1 & & & & & \\
\hline$\ldots$ & & & & & \\
\hline 18 & & & & & \\
\hline
\end{tabular}

